Int. J. Curr. Res. Med. Sci. (2017). 3(11): 5-10

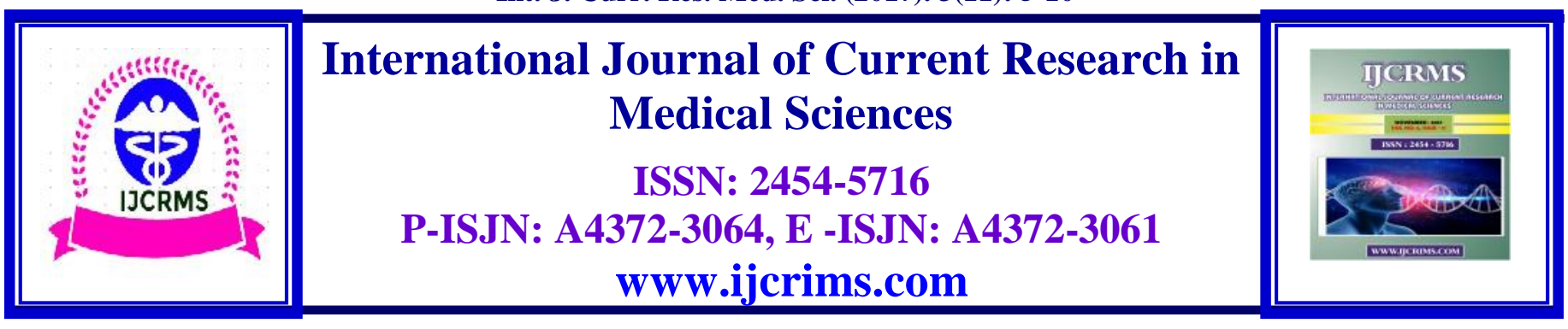

\title{
In-vitro Evaluation of Immune Enhancing Potential of Novel siddha formulation Rasa Chendhuram using Murine Macrophage RAW 264.7 Cell Line Model
}

\author{
R. Kalaimani**1, M. Mohammed Mustafa ${ }^{2}$ \\ ${ }^{* 1}$ P.G.Scholar, Post Graduate Department of Sirappu Maruthuvam, Government Siddha Medical College, \\ Arumbakkam, Chennai 600 106, Tamil Nadu, India. \\ ${ }^{2}$ Reader and Head of the Department of Sirappu Maruthuvam, Government Siddha Medical College, \\ Arumbakkam, Chennai 600 106, Tamil Nadu, India. \\ Corresponding Author: Dr. R. Kalaimani, Post Graduate Department of Sirappu Maruthuvam, \\ Government Siddha Medical College, Arumbakkam, Chennai 600 106, Tamil Nadu, India. \\ E-mail: kalaisiddha@gmail.com
}

\begin{abstract}
Immunomodulation is a process of considerable change in the immune response and may involve expression, amplification of any part or phase in the immune response. Modulation may be very specific and limited to a given antigen/agent or non-specific, with a great effect on immune response. Macrophages have been known to play an important role in the host protection against a wide range of tumors and microorganisms. Macrophages also presents antigen to lymphocytes during the development of specific immunity and serve as supportive accessory cells to lymphocytes. When activated, macrophages increase the phagocytic activity and release various materials such as cytokines and reactive intermediates and then carry out non-specific immune responses. In spite of incredible advances in modern science, technology and allopathic medicine a large we are unable to provide quality healthcare to all. Hence in recent times scientist started migrating towards alternate medicines from traditional medicinesin Ayushsystem, particularly siddha formulations. Murine macrophage cell line RAW 264.7 is widely utilized model for evaluating the In-vitro immunomodulatory efficacy of the several siddha formulations. The main aim of the present investigation is to evaluate the In-vitro immunomodulatory potential of the traditional siddha formulation Rasa Chendhuram (RC) a metalo mineral preparation in Macrophage cell line RAW 264.7 using lipopolysaccharide (LPS) $(1 \mu \mathrm{g} / \mathrm{mL})$ as control. LPS induced nitrite production used an indicator for evaluating the level of phagocytosis. The concentration was measure spectrophotometrically at $540 \mathrm{~nm}$. The result obtained from the present investigation indicates that the drug RC exhibit significant decrease in the level of nitrites in the cell line medium from $952.38 \mu \mathrm{g}$ to $373.32 \mu \mathrm{g}$. The results clearly indicate that the formulation RC possess significant immune boosting properties and suggest usefulness in the disorder of immunological origin such as Parangisogai, Kiranthi (chronic ulcers), Kuttarogam ( skin diseases), Thaadhunattam, Lingaputtru and Vippurudhi (cancer).
\end{abstract}

Keywords: Immunomodulation, In-vitro, Siddha formulation, Rasa Chendhuram, Macrophages, RAW 264.7 cell line, Lipopolysaccharide, Nitrites. 


\section{Introduction}

Immunity is the body's natural defense system against various infectious diseases. The factors which trigger immunity include previous infection, immunization, and various external stimuli. Besides, immunity is capable of discriminating among body's own proteins/cells and foreign entities. As soon as the foreign particle is identified, the collective and coordinated response of specific cells and mediators against strange substances constitutes the immune response.

Traditional medicines particularly siddha preparations considered as a major healthcare provider around the globe particularly in rural and remote areas. A large section of people depends on such medicine for their primary healthcare mainly in underdeveloped or developing countries. Indian traditional medicinal system like Siddha, Ayurveda and Unani has a very rich history of their effectiveness; modern research also acknowledged the importance of such medicine. Indian traditional medicine, herbs and herbomineral formulations are also considered as a vital source of new drug [3].

Rasa chendhuram is a traditional siddha formulation comprises of mercury, sulphur and arsenic trisulphide which majorly acts as a immune booster by mediating the enzyme catalysis action as most of the biological activity was exerted and mediated by the protein target called enzymes. According to the established physiology and theories metal plays a vital role in mediating the enzyme function.

Stimulation of the immune response is preferred for certain people such as immunocompromised patient, whereas, suppression of immune response is consideration for others such as transplant recipient or inflammatory diseases. Immunomodulatory biomolecules of animal as well as plant sources activates the immune response in an organism against any foreign invaders by mimicking the immune reactions [4].
The main aim of the present investigation is to evaluate the In-vitro immunomodulatory potential of the traditional siddha formulation Rasa Chendhuram (RC) a metallic mineral preparation in Macrophage cell line RAW 264.7 using lipopolysaccharide (LPS) $(1 \mu \mathrm{g} / \mathrm{mL})$ as control. This research work will be an initiative of developing documentary evidence on biological activity of the formulation Rasa Chendhuram for the future researchers.

\section{Materials and Methods}

\subsection{Source of raw drugs:}

The Required raw materials were procured from a well reputed indigenous drug shop from Parrys corner, Kanda Samy Temple, Chennai, Tamil Nadu, India .All raw drugs were authenticated by respective authorities.

\subsection{Ingredients}

The siddha formulation Rasa Chendhuram comprises of the following ingredients

$\begin{array}{lc}\text { Rasam (Hydragyram/ Mercury) } & -35 \mathrm{gm} \\ \text { Gandhagam (Sulphur) } & -35 \mathrm{gm} \\ \text { Aridharam (Arsenic Trisulphide) } & -35 \mathrm{gm}\end{array}$

\subsection{Formulation of Trial drug Rasa Chendhuram [5]}

The above mentioned purified raw drugs was grounded well in the stone mortar and made as a fine powder. Followed by this the fine powder was fried well at fixed temperature as described. Finely powdered egg shell powder was spread on to the bottom of mud pot as a base layer above which finely powdered drug was placed and another layer of finely powdered egg shell powder was poured on to its top like a sandwich. Then the setup was heated with kukkudapudam (10 cow dung cakes) to make it as Chendhuram. The finished product thus obtained was stored in an air tight container. 
Dose

Adjuvant / Vehicle :Palm jaggery.

Disease Indication :Parangisogai, Kiranthi, Kuttarogam, Thaadhunattam, Lingaputtru, Vippurudhi.

\subsection{Cell culture, measurement of cell viability [6]}

Macrophage cell line RAW 264.7 was obtained from National Center for Cell Science (Pune, India) and cultured in DMEM supplemented with fetal bovine serum (10\%) containing penicillinstreptomycin $(10 \%)$ at $37^{\circ} \mathrm{C}$ in a humidified atmosphere containing $5 \% \mathrm{CO} 2$. Cells were plated at a density of $1 \times 104$ cells/well in 25 or $75 \mathrm{~cm} 2$ flasks, or in 96-well plate overnight. RAW 264.7 were grown to $60 \%$ confluence followed by activation with $1 \mu \mathrm{L}$ lipopolysaccharide (LPS) $\quad(1 \mu \mathrm{g} / \mathrm{mL})$. LPS stimulated RAW cells were exposed with different concentration $(25,50,100 \mu \mathrm{g} / \mathrm{mL})$ of the test sample and incubated for 24 hours. After 24 hours of incubation the cells were digested and centrifugation was done at $6000 \mathrm{rpm}$ for 10 minutes. Supernatant was discarded and cells were then re suspended in $200 \mu \mathrm{l}$ of cell lysis buffer (0.1M TrisHCl, 0.25M EDTA, 2M NaCl, $0.5 \%$ Triton $\mathrm{x}-100)$. The samples were then kept at $4^{\circ} \mathrm{C}$ for 20 minutes. After incubation, the Immuno modulatory response was performed by estimating nitrite levels in the cell lysate.

\subsection{Estimation of Cellular Nitrite Levels [7]}

The level of nitrite level was estimated by the method described previously. To $0.5 \mathrm{~mL}$ of cell lysate, $0.1 \mathrm{~mL}$ of sulphosalicylic acid was added and vortexed well for 30 minutes. The samples were then centrifuged at 5,000 rpm for 15 minutes. The protein-free supernatant was used for the estimation of nitrite levels. To $200 \mathrm{~L}$ of the supernatant, $30 \mathrm{~L}$ of $10 \% \mathrm{NaOH}$ was added, followed by 300 L of Tris-HCl buffer and mixed well. To this, 530 L of Griess reagent was added and incubated in the dark for 10-15 minutes, and the absorbance was read at $540 \mathrm{~nm}$ against a Griess reagent blank. Sodium nitrite solution was used as the standard. The amount of nitrite present in the samples was estimated from the standard curves obtained.

\section{Results}

It was observed that there was dose dependent decrease in the nitrite level in RAW 264.7 medium were observed at the concentration ranges from 25 to $100 \mu \mathrm{g} / \mathrm{ml}$ of the test drug $\mathrm{RC}$. Lipopolysaccharide (LPS) $(1 \mu \mathrm{g} / \mathrm{mL})$ treated well was served as control with maximum nitrite level of about $952.38 \mu \mathrm{g}$. The formulation $\mathrm{RC}$ at the dose of $25 \mu \mathrm{g} / \mathrm{ml}$ shown significant decrease in nitrite level of about $573.21 \mu \mathrm{g}$ similarly at the concentration of $50 \mu \mathrm{g} / \mathrm{ml}$ it shows $428.17 \mu \mathrm{g}$ and the maximum percentage decrease of nitrite level of about $373.23 \mu \mathrm{g}$ were observed at $100 \mu \mathrm{g} / \mathrm{ml}$. The results were tabulated in table 1 and shown in Figure 1.

Table 1: Effect of Siddha Formulation Rasa Chendhuramon Nitrite level RAW 264.7 Cell line.

\begin{tabular}{|c|c|c|}
\hline Concentration $(\boldsymbol{\mu g} / \mathbf{m l})$ & Absorbance at 540nm & $\begin{array}{c}\text { Concentration of Nitrites } \\
(\boldsymbol{\mu g})\end{array}$ \\
\hline Control $(\mathrm{LPS} 1 \mu \mathrm{g} / \mathrm{mL})$ & 0.1924 & 952.38 \\
\hline RC 25 & 0.1158 & 573.21 \\
\hline RC 50 & 0.0865 & 428.17 \\
\hline RC 100 & 0.0754 & 373.23 \\
\hline
\end{tabular}


Figure 1: Effect of Siddha Formulation Rasa Chendhuram on Nitrite level in murine Macrophage RAW 264.7 Cell line

Effect of Siddha formulation Rasa Chendhuram on Nitrite Concentration in RAW 264.7 cell lines

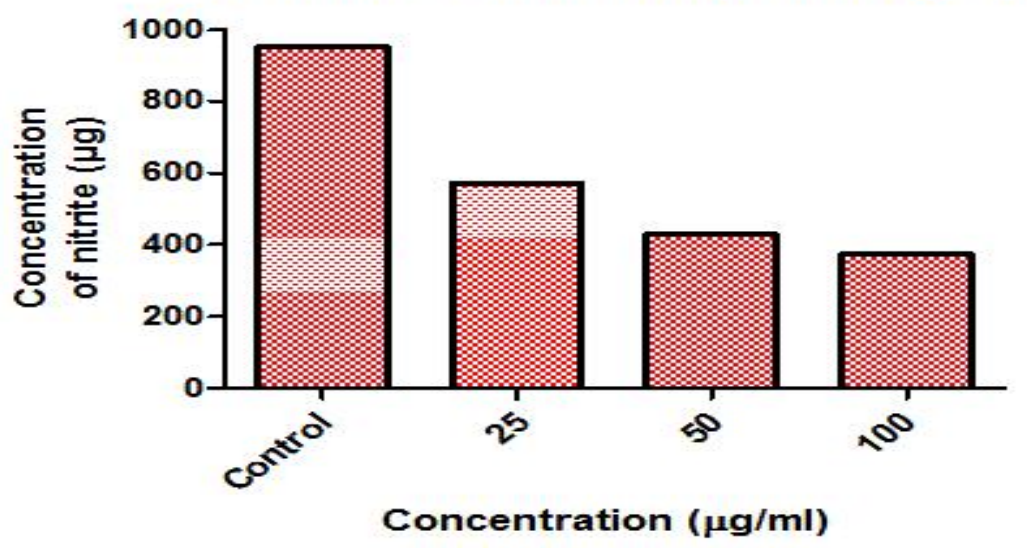

\section{Discussion}

The function and efficiency of the immune system are influenced by various exogenous and endogenous factors resulting in either immunosuppression or immunostimulation. Several agents possessing an activity to normalize or modulate pathophysiological processes are called immunomodulators. The biomolecules of synthetic or biological origin capable of modulating, suppressing and stimulating any components of adaptive or innate immunity are known as immunomodulators, immunorestoratives, immunoaugmentors, or biological response modifiers.

Immunomodulators are generally categorized into immunoadjuvants, immunostimulants, and immunosuppressants in clinical practice. Immunoadjuvants are specific immune stimulators which enhance the efficacy of vaccine. Agents that activate or induce the mediators or components of immune system are called as immunostimulants. The resistance against autoimmunity, cancer, allergy, and infection is enhanced by immunostimulants. On the other hand, immunosuppressants are the molecules that inhibit the immune system, can be used to control the pathological immune reaction subsequent to organ transplantation. Additionally, these agents can also be used in the treatment of infection-associated immunopathology, hypersensitivity reactions, and autoimmune diseases. A number of monoclonal antibodies and chemically synthesized compounds are also being used as immunomodulators [8].

Modulation of the immune functions either by stimulation or suppression may help to maintain a disease-free state [9]. Herbomineral and pure minerals used in traditional medicines are demonstrated to modulate either cellular or humoral or both arms of the immune responses of the body [10]. Siddha formulations contain several chemical moiety, of which some may have immunosuppressive activity, whereas others possess immunostimulatory action. The biological activity of a rasa chendhuram is greatly dependent on its chemical nature and composition of the major active metabolites. Therefore, the quantitative determination of specific known bioactive compounds in siddha mineral formulation is essential for quality control and dose determination in the toxicological and biological activity studies.

Antibody molecules, produced from B lymphocytes and plasma cells play a central role in humoral immune response. In humoral immunity, IgG and IgM are the major immunoglobulins involved in the complement activation, opsonization, neutralization of toxins, etc [11]. Phagocytosis provides the body's firstline defense mechanism by eliminating microorganisms, inhaled carbon particles, malignant cells, tissue debris and other 
non-biological foreign materials [12]. The process mainly involves specialized immune cells including neutrophils, macrophages and dendritic cells collectively called phagocytes [13].

The Indian traditional system of medicines, especially siddha, plays a significant role in disease prevention and promotion of health towards longevity with better quality of life. The concept of "Chendhuram" drugs of siddha complemented by traditional findings suggested that the "Rasa Chendhuram" drugs may influence the host immunity and resistance against infections and other diseases. Results obtained from the present investigation clearly reveals that there was dose dependent decrease in the nitrite level in RAW 264.7 medium were observed at the concentration ranges from 25 to $100 \mu \mathrm{g} / \mathrm{ml}$ of the test drug RC. Lipopolysaccharide (LPS) $(1 \mu \mathrm{g} / \mathrm{mL})$ treated well was served as control with maximum nitrite level of about $952.38 \mu \mathrm{g}$. The formulation $\mathrm{RC}$ at the dose of $25 \mu \mathrm{g} / \mathrm{ml}$ shown significant decrease in nitrite level of about $573.21 \mu \mathrm{g}$ similarly at the concentration of 50 $\mu \mathrm{g} / \mathrm{ml}$ it shows $428.17 \mu \mathrm{g}$ and the maximum percentage decrease of nitrite level of about $373.23 \mu \mathrm{g}$ were observed at $100 \mu \mathrm{g} / \mathrm{ml}$.

\section{Conclusion}

The immunomodulatory characteristics of siddha therapy have gathered attention of researchers. Herbo mineral and metallic preparations may provide us with valuable entities to develop as novel immunomodulatory agents to supplement the present chemotherapies. Result of the present investigation clearly projects that the siddha formulation Rasa Chendhuram significantly decreases the level of nitrites from $952.38 \mu \mathrm{g}$ to $373.23 \mu \mathrm{g}$ at the concentration $100 \mu \mathrm{g} / \mathrm{ml}$ which is considered to be one of the most important indicator of phagocytosis in the macrophage cell lines. Hence it may conclude that the formulation Rasa Chendhuram may be used as an Immunomodulators for clinical management of immune compromised diseases like Parangisogai, Kiranthi, Kuttarogam, Thaadhunattam, Lingaputtru and Vippurudhi.

\section{References}

1. Baxter D. Active and passive immunity, vaccine types, excipients and licensing. Occup. Med. 2007;57: 552-556.

2. Vesely MD, Kershaw MH, Schreiber RD, Smyth MJ. Natural innate and adaptive immunity to cancer. Annu. Rev. Immunol. 2011;29: 235-271.

3. Saikat Sen. Revival, modernization and integration of Indian traditional herbal medicine in clinical practice: Importance, challenges and future. J Tradit Complement Med. 2017; 7: 234-244.

4. Maushmi S. Kumar. Immunomodulatory Potential of a Marine Sponge Spongosoriteshalichondrioides. Turkish Journal of Fisheries and Aquatic Sciences.2012;12:67-71.

5. Pulipaanivaithiyam $-500,5^{\text {th }}$ edition- 1970 , page.no - 68

6. Oh K, Moon HG, Lee DS, Yoo YB. Tissue transglutaminase- interleukin- 6 axis facilitates peritoneal tumor spreading and metastasis of human ovarian cancer cells. Lab Anim Res.2015;31:188-197.

7. Sathya M .Invitro screening of a Poly Herbal Siddha Formula for Its Anti-Inflammatory Properties. RJPBCS.2014;5: 992-998.

8. Puri A, Saxena R. Immunostimulant activity of Nyctanthes arbor-tristis L. J. Ethnopharmacol.1994; 42: 31-37

9. Shukla S, Mehta A, John J, Mehta P, Vyas SP. Immunomodulatory activities of the ethanolic extract of Caesalpiniabonducella seeds. J Ethnopharmacol .2009; 125:252-256.

10. Plaeger SF. Clinical immunology and traditional herbal medicines. ClinDiagn Lab Immunol.2003; 10:337-338.

11. Khajuria A, Gupta A, Garai S, Wakhloo BP. Immunomodulatory effects of two sapogenins 1 and 2 isolated from Luffacylindrica in Balb/C mice. Bioorg Med ChemLett .2007; 17:1608-1612.

12. Pavelka M, Roth J. Functional Ultrastructure: Atlas of Tissue Biology and Pathology. 2nd ed. New York: Springer-Wien; 2010. 
13. De Franco AL, Locksley RM, Robertson M. Immunity: The Immune Response in Infectious and Inflammatory Disease. Ist Ed. New York: Oxford University Press; 2007.

\begin{tabular}{|c|l|}
\hline \multicolumn{2}{|c|}{ Access this Article in Online } \\
\hline Quick Response Code & Website: \\
& www.ijcrims.com \\
\hline Subject: \\
\hline
\end{tabular}

How to cite this article:

R. Kalaimani, M. Mohammed Mustafa. (2017). In-vitro Evaluation of Immune Enhancing Potential of Novel siddha formulation Rasa Chendhuram using Murine Macrophage RAW 264.7 Cell Line Model. Int. J. Curr. Res. Med. Sci. 3(11): 5-10.

DOI: http://dx.doi.org/10.22192/ijcrms.2017.03.11.002 